Proceedings

\title{
Enhancement of Power Quality Using Voltage and Hall Effect Current Sensors Applied on Controlled Single-Phase Active Power Filter ${ }^{\dagger}$
}

\author{
Felipe Barnabé, Marco Rocha *(D), Guilherme Clerice \\ Botucatu College (UNIBR), Botucatu 18611-020, Brazil; felipe.barnabe@alu.unibrbotucatu.com.br (F.B.); \\ guilherme.clerice@unibrbotucatu.com.br (G.C.) \\ * Correspondence: marco.rocha@unibrbotucatu.com.br \\ + Presented at the 7th International Electronic Conference on Sensors and Applications, 15-30 November 2020; \\ Available online: https:/ / ecsa-7.sciforum.net/.
}

Published: 15 November 2020

\begin{abstract}
Switched-mode power supply and semiconductor devices have been gaining more and more applicability in the industrial scenario. With the massive use of these devices, several problems related to power quality and equipment degradation have been arising, caused mainly by the harmonic content present in current and voltage. Power quality problems have direct implications for business productivity, causing high economic losses. Therefore, it is mandatory to develop solutions that mitigate these problems. Active Power Filters (APF) are power electronic equipment capable of compensating power quality problems. Also, presents the ability to dynamically adjust their modes of operation in response to changes in load or the power systems. Active power filters present the economical advantage of using the same current and voltage sensors already existing in a power system. Aiming to develop an APF for single-phase applications, this work proposes a shunt controlled active power filter using hall effect current and voltage sensor aiming to compensate harmonic currents provided by nonlinear loads. It was proposed two proportional-integral compensators, where the external loop is responsible for link-CC control and the inner loop is responsible for current compensation. The results show the applicability of the proposed APF since all harmonic content was filtered.
\end{abstract}

Keywords: active power filter; hall effect current sensor; nonlinear loads

\section{Introduction}

The advent of power electronics allowed the improvement of semiconductor devices, generating a crucial change in the drive, control and power level of various types of loads. Therefore, power electronic systems are used increasingly in a wide range of application fields, such as variable-speed drives, switched sources, rectifiers, and others. Also, they are widely used for administrative equipment such as personal computers [1]. However, power semiconductor devices bring as a disadvantage the appearance of harmonics in the electrical grid [2]. These harmonics are originated by the non-linear conduction of the electronic switches, causing distortions in the voltage and current waveform. Due to this non-linear current, the system has to supply a large amount of reactive power [3].

In this context, grid harmonics cause problems such as voltage regulation and stability, deterioration of power quality, and increasing system losses. Due to the enormous financial and operational impact caused by the presence of reactive energy in the grid, the correct control and mitigation of reactive power and harmonic is a more than necessary topic nowadays $[4,5]$. 
To solve problems related to loads with high harmonic content, is used active power filters (APFs) [6]. APFs are used to compensate current distortions from non-linear loads. This is accomplished by injecting harmonic currents into the grid as phase opposition to the harmonic currents generated by the load [7]. In addition, active power filters present the economical advantage of using the same current and voltage sensors already existing in a power systems [8].

In this context, this work proposes a shunt controlled active power filter using hall effect current and voltage sensor aiming to mitigate harmonic current content from non-linear loads. To achieve this goal, a non-linear load (emulated through a rectifier) was powered by a single-phase voltage supply. At the common coupling point, a shunt active power filter, consisting of a DC bus and four IGBT switches, was set in parallel with the load. The proposed control system for the switching of the electronic devices was achieved through the acquisition of the current and voltage signals from the grid by the hall effect sensors. Also, it was proposed two proportional-integral compensators, where the external loop is responsible for link-DC control, and the inner loop is responsible for current compensation. The harmonic mitigation was achieved by assessing these current and voltage signals from hall effect sensors in the proposed AFP. This control technique allows the compensation of currents generated by non-linear loads.

In conclusion, based on the relevance of the power electronics devices in the industrial scenario, it is crucial to develop systems capable to mitigate reactive power and harmonic content [9]. Also, the control algorithm proposed in this work proved to be an efficient technique for the APF system. The hall effect sensors applied to signal acquisition are considerably useful due to its application in power systems, allowing the development of viable active power filters. Finally, the results showed the applicability of the proposed APF since all harmonic content was filtered.

This paper is divided into six sections. Sections 2 and 3 describe the hall effect sensors and the control algorithm, respectively. Section 4 describes the experimental setup that was carried out in this work. Section 5 contains the results, and Section 6 presents the conclusions.

\section{Hall Effect Sensors}

A Hall Effect Sensor is a transducer that, when under application of a magnetic field, responds with a variation in its output voltage [10].

The Hall Effect is a property that manifests itself in a conductor when a magnetic field perpendicular to the current flow is applied on it. When this occurs, a voltage in the conductor is generated, called Hall Voltage. This voltage has a perpendicular direction to the magnetic field and current, and is proportional to the magnetic flux density and current. The magnetic field applied causes a gradient of carrier concentration in the entire conductor. When the number of carriers on one side of the conductor is greater than the other, then this voltage will appear. Hall voltage amplitude varies with current and magnetic field [10].

\section{Control Technique}

The control algorithm developed in this article is based on the proportional-integral compensators. The following subsections will present the the active power filter and the control algorithm.

\subsection{Active Power Filter}

The active power filter consists of injecting compensation currents into the electrical grid in order to cancel the harmonic and reactive power generated by the load. The main goal of the APF is that the currents of the load and the currents of the active power filter result in sinusoidal grid currents, i.e., no harmonic content [7]. A typical system setup is shown in Figure 1.

The structure chosen for the assembly of the active power filter was the full bridge voltage source inverter. This topology consists of four semiconductor switches (IGBT) and a DC bus. 


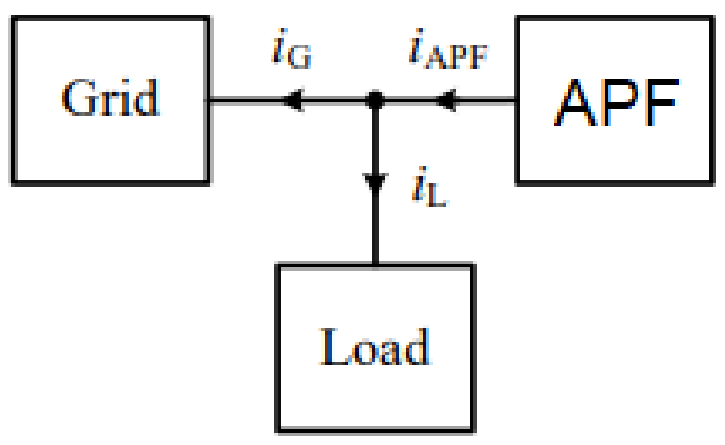

Figure 1. Active Power Filter.

\subsection{Control Algorithm}

The proposed control algorithm is based on two proportional-integral compensators, where the external loop is responsible for link-DC control and the inner loop is responsible for current compensation. The block diagram of the control system is shown in Figure 2.

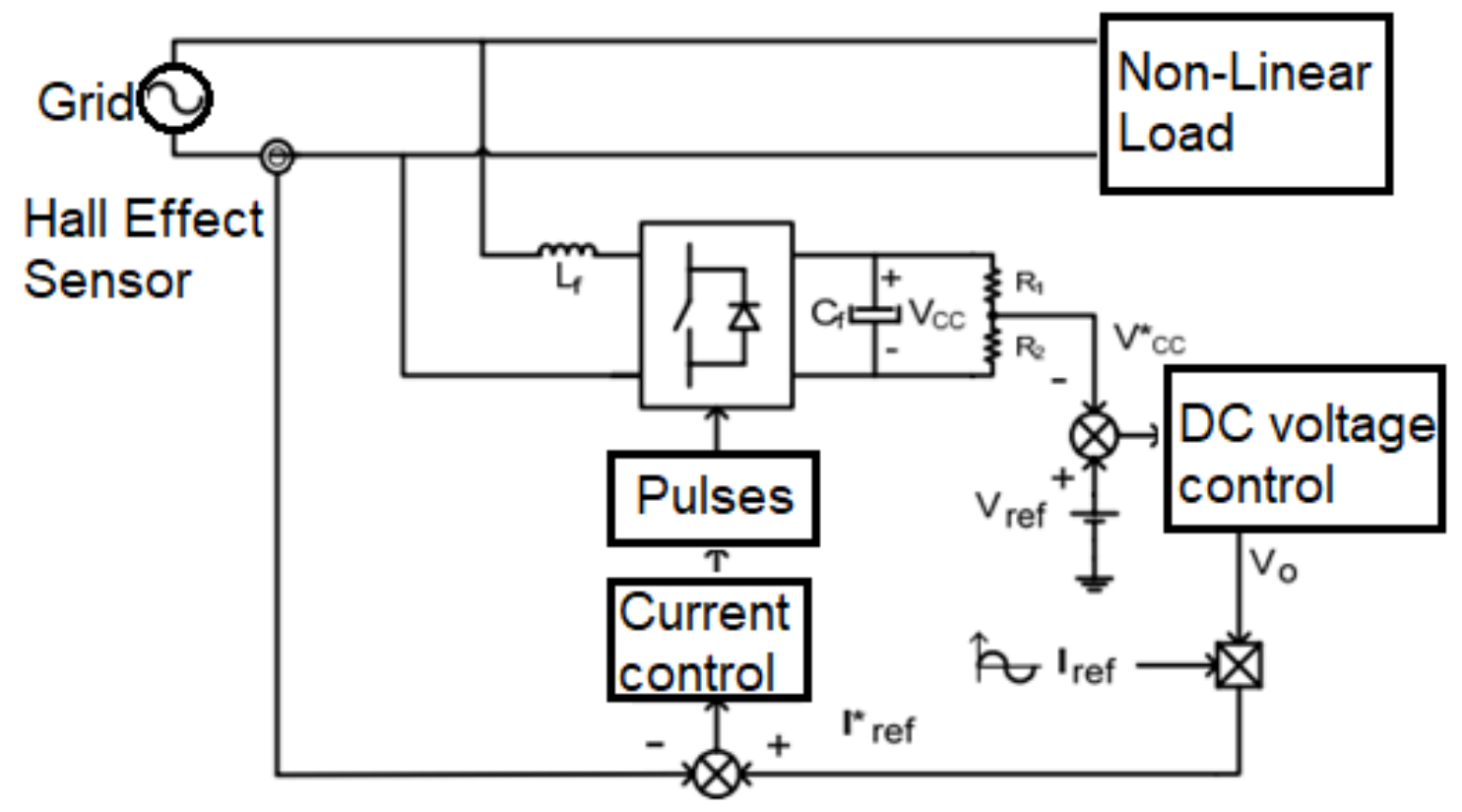

Figure 2. Control Algorithm Block Diagram.

According to the experimental assembly specifications shown in the following section, the control system was designed. For the practical implementation of the proportional-integral controller, operational amplifiers were used. With this, the external loop has the function of controlling the DC bus voltage at a specific value and providing the current reference for the internal loop. This loop aims to generate the necessary pulses for switching IGBT devices, mitigating current harmonics. The structure of the proportional-integrated controllers, as its values are presented in Figure 3. 


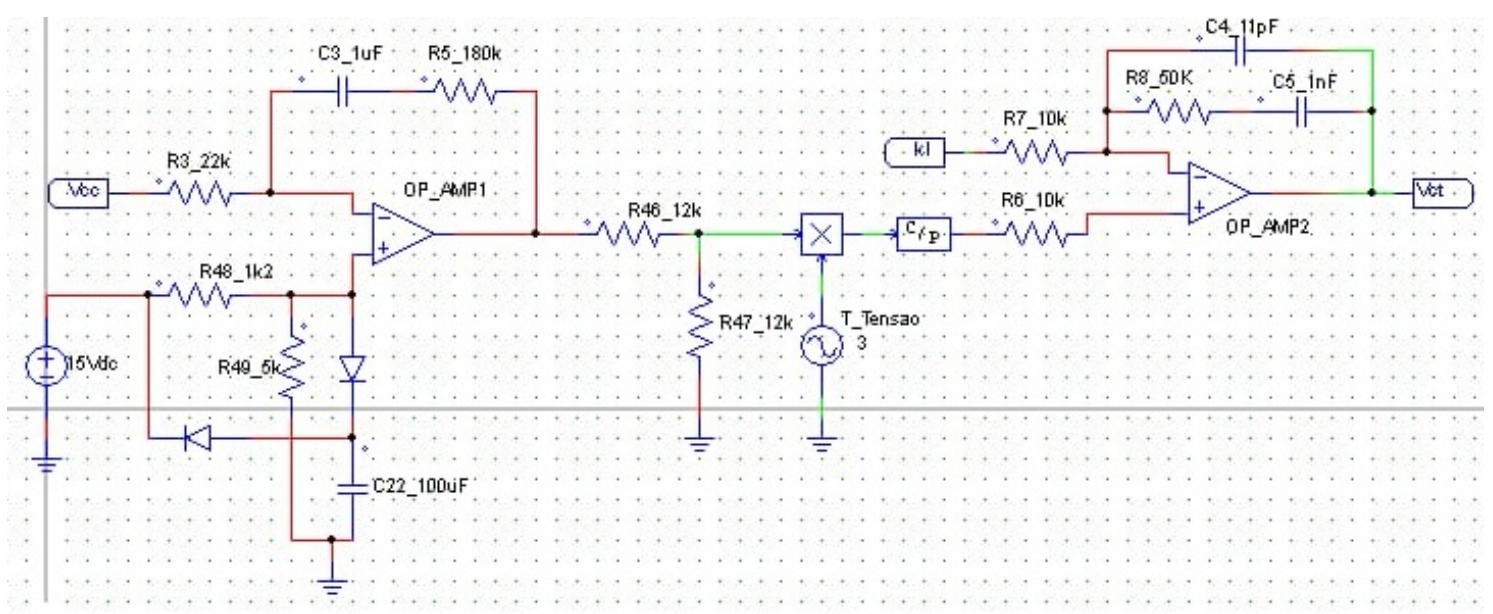

Figure 3. Proportional-Integral Design.

\section{Experimental Setup}

For the implementation of the active power filter, a highly non-linear load was used. The filter in operation should reduce the harmonic current distortions to values lower than 10 per cent. The load is defined by a rectifier with a capacitor and a resistor in parallel on the DC side of the rectifier. The capacitor used was $1 \mathrm{mF}$ with a resistance of $200 \mathrm{ohms}$. Therefore, the load has an active power of $153.6 \mathrm{~W}$; reactive power of $476 \mathrm{VAr}$ and power factor of 0.302 . The grid power supply is $127 \mathrm{Vrms}$ with $60 \mathrm{~Hz}$ frequency. The DC bus voltage is $350 \mathrm{~V}$ and the switching frequency of IGBTs is $30 \mathrm{kHz}$. The structure of the APF used is shown in Figure 4. The experimental setup is shown in Figure 5

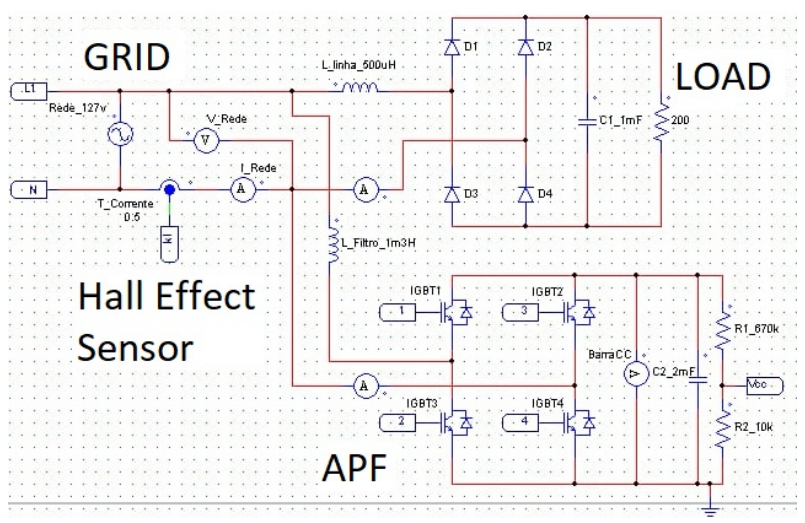

Figure 4. APF Proposed Topology.

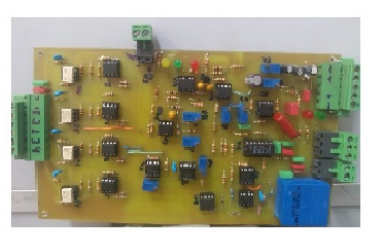

a)

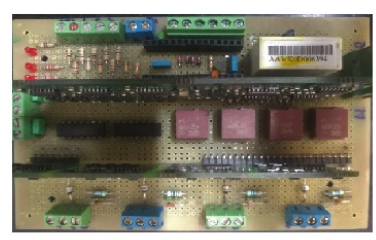

b)

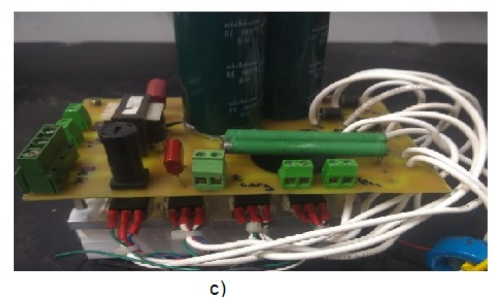

Figure 5. (a) control setup; (b) instrumentation and measure; (c) IGBT devices. 


\section{Results}

The load current waveform is shown in the Figure 6a. It is noted that its behavior is highly non-linear. The Figure $6 \mathrm{~b}$ presents the content of the fast Fourier transform (FFT) of this waveform, in which it is possible to notice its high harmonic content. After the APF application, it is possible to observe that the load current was filtered, and all this harmonic content now flows through the filter. Therefore, the grid current present sinusoidal shape, as shown in the Figure 7a. This sinusoidal behavior is evidenced by the FFT of this signal, presented in the Figure $7 \mathrm{~b}$.

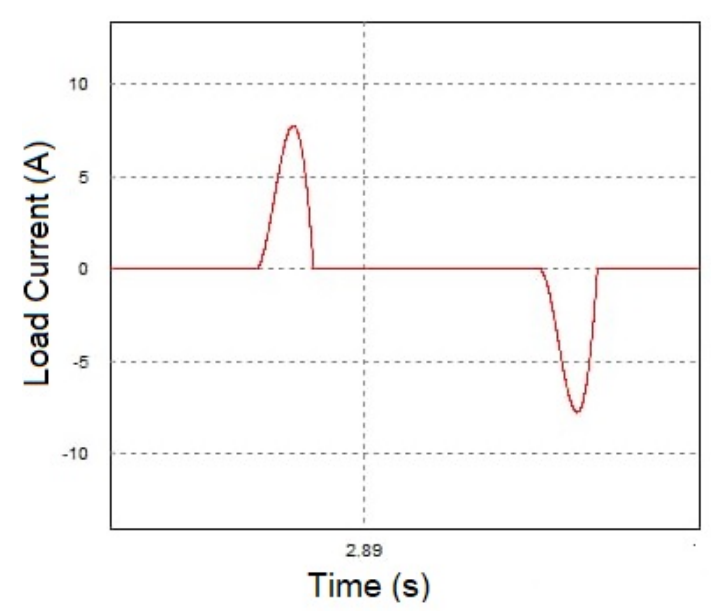

a)

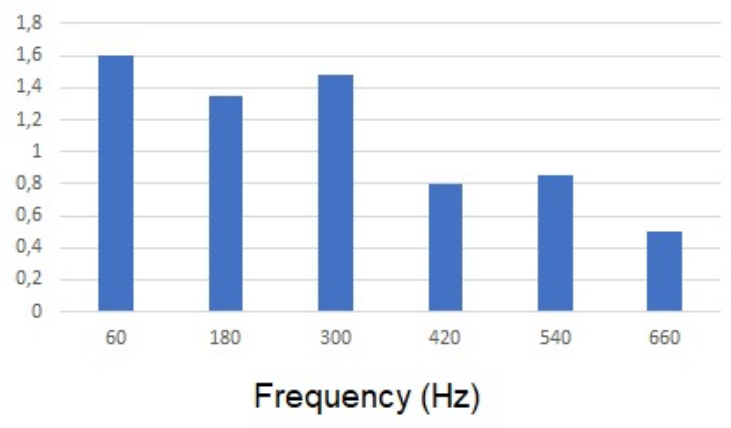

b)

Figure 6. (a) Load Current; (b) Load Current FFT.

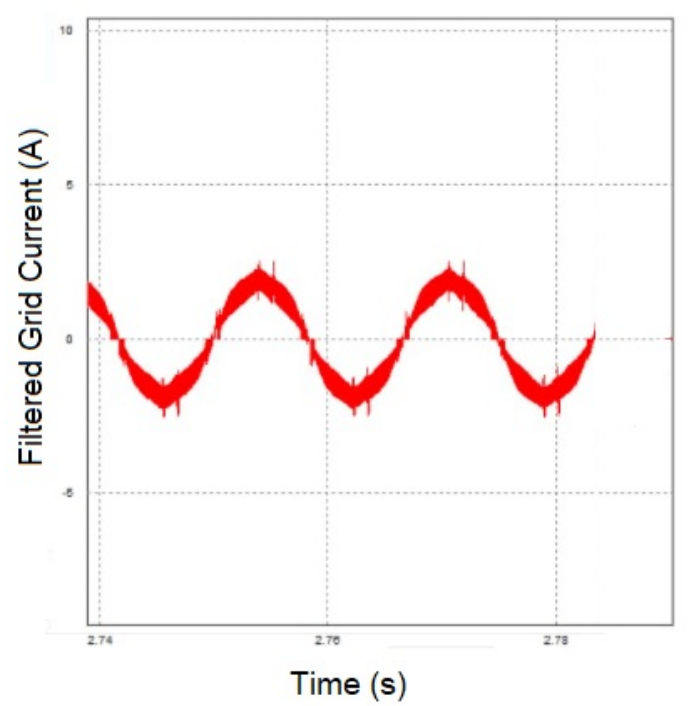

a)

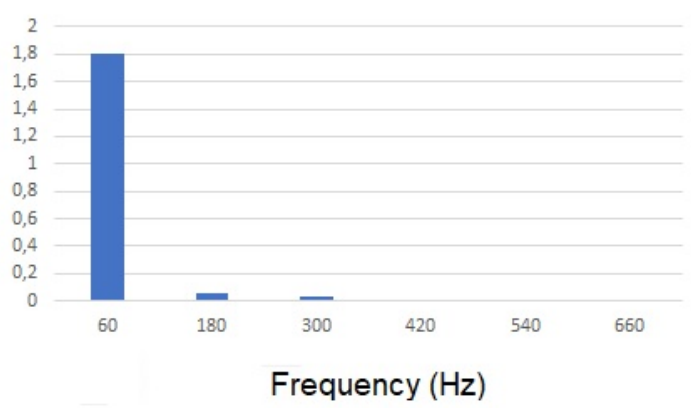

b)

Figure 7. (a) Grid Current; (b) Grid Current FFT.

\section{Conclusions}

Due to the relevance of power electronics devices in production lines and industrial environment, active power filters are powerful tools to improve the power quality. Therefore, in this work, it was developed an active power filter that uses a current hall effect sensor to provide the current signals for the control systems.

The application of the technique has stood out for providing precise and high accuracy results, as proved by FFT analysis of the grid and load current. It allowed to mitigate the harmonic content 
present in the load. The compensation was correct achieved, once the total harmonic distortion was lower than 10 per cent, as this work proposed.

In future works, a three phase system can be assess. Also, it can be proposed the application of the APF in renewable energy systems, as wind and photo-voltaic.

Conflicts of Interest: The authors declare no conflict of interest.

\section{References}

1. Falck, J.; Felgemacher, C.; Rojko, A.; Liserre, M.; Zacharias, P. Reliability of Power Electronic Systems: An Industry Perspective. IEEE Ind. Electron. Mag. 2018, 12, 24-35. doi:10.1109/mie.2018.2825481.

2. Bose, B.K. Power Electronics, Smart Grid, and Renewable Energy Systems. Proc. IEEE 2017, 105, 2011-2018. doi:10.1109/jproc.2017.2745621.

3. Mishra, A.K.; Das, S.R.; Ray, P.K.; Mallick, R.K.; Mohanty, A.; Mishra, D.K. PSO-GWO Optimized Fractional Order PID Based Hybrid Shunt Active Power Filter for Power Quality Improvements. IEEE Access 2020, 8, 74497-74512. doi:10.1109/access.2020.2988611.

4. Ferreira, S.C.; Gonzatti, R.B.; Pereira, R.R.; da Silva, C.H.; da Silva, L.E.B.; Lambert-Torres, G. Finite Control Set Model Predictive Control for Dynamic Reactive Power Compensation With Hybrid Active Power Filters. IEEE Trans. Ind. Electron. 2018, 65, 2608-2617. doi:10.1109/tie.2017.2740819.

5. Rocha, M.A.; de Souza, W.G.; Serni, P.J.A.; Andreoli, A.L.; Clerice, G.A.M.; da Silva, P.S. Control of three-phase PWM boost rectifiers using proportional-resonant controllers. In Proceedings of the 2018 Simposio Brasileiro de Sistemas Eletricos (SBSE), Niteroi, Brazil, 12-16 May 2018. doi:10.1109/sbse.2018.8395803.

6. Hou, S.; Fei, J.; Chen, C.; Chu, Y. Finite-Time Adaptive Fuzzy-Neural-Network Control of Active Power Filter. IEEE Trans. Power Electron. 2019, 34, 10298-10313. doi:10.1109/tpel.2019.2893618.

7. Bosch, S.; Staiger, J.; Steinhart, H. Predictive Current Control for an Active Power Filter With LCL-Filter. IEEE Trans. Ind. Electron. 2018, 65, 4943-4952. doi:10.1109/tie.2017.2772176.

8. Pandey, S.K.; Singh, B. Hybrid DSC with Compensation Capability Based Control for Grid Integrated SPV System. In Proceedings of the 2020 IEEE 9th Power India International Conference (PIICON), Sonepat, India, 28 February-1 March 2020. doi:10.1109/piicon49524.2020.9113069.

9. Kashif, M.; Hossain, M.; Zhuo, F.; Gautam, S. Design and implementation of a three-level active power filter for harmonic and reactive power compensation. Electr. Power Syst. Res. 2018, 165, 144-156. doi:10.1016/j.epsr.2018.09.011.

10. Ramsden, E. Hall-Effect Sensors : Theory and Applications; Elsevier: Amsterdam, The Netherlands; Newnes: Boston, MA, USA, 2006.

Publisher's Note: MDPI stays neutral with regard to jurisdictional claims in published maps and institutional affiliations.

(C) 2020 by the authors. Licensee MDPI, Basel, Switzerland. This article is an open access article distributed under the terms and conditions of the Creative Commons Attribution (CC BY) license (http:/ / creativecommons.org/licenses/by/4.0/). 